\title{
Relation between soluble interleukin 2 receptor and clinical findings in patients with systemic lupus erythematosus
}

\author{
YOSHIAKI TOKANO, ${ }^{1}$ ATSUKO MURASHIMA, ${ }^{1}$ \\ YOSHINARI TAKASAKI, ${ }_{1}$ HIROSHI HASHIMOTO, ${ }^{1}$ KO OKUMURA, ${ }^{2}$ \\ AND SHUNICHI HIROSE
}

From the Division of Rheumatology, Department of ${ }^{1}$ Internal Medicine and ${ }^{2}$ Immunology, Juntendo University School of Medicine, Tokyo, Japan

SUMMARY The concentration of soluble interleukin 2 receptor (IL-2R) was determined in the serum of 54 patients with systemic lupus erythematosus (SLE) by an enzyme linked immunosorbent assay (ELISA) using two monoclonal antibodies with the IL-2R. Concentrations of soluble IL-2R in the serum of the patients with SLE (study group) were significantly higher than in 20 normal subjects (control group). The relation between concentrations of soluble IL-2R and clinical findings was investigated. The concentration of soluble IL-2R showed no particular relation with the clinical manifestations and did not correlate with the level of anti-DNA antibody or $\mathrm{CH}_{50}$. Significant correlation between the concentration of soluble IL-2R and disease activity did exist, however. Furthermore, the concentration of soluble IL-2R in some cases changed simultaneously with the disease activity. Thus the concentration of soluble IL-2R may serve as a new clinical indicator of disease activity in patients with SLE.

It is known that patients with systemic lupus erythematosus (SLE) have various immunological abnormalities. Thus patients with SLE have B cell abnormalities, such as polyclonal B cell activation, and $\mathrm{T}$ cell abnormalities have also been reportedfor example, change in $\mathrm{CD} 4 / 8$ ratio, ${ }^{1}$ decrease in the response to various mitogens (phytohaemagglutinin, concanavalin $\mathrm{A}$, etc), non-response to autologous mixed lymphocyte reaction, ${ }^{2} 3$ and decrease in the production of interleukin $2 .^{45}$ Furthermore, other studies have shown that patients with SLE have activated $T$ cells, as indicated by Ia positive $T$ cells (HLA-DR positive $T$ cells). ${ }^{67}$

It is known that interleukin 2 receptor (IL-2R) is detected on the cellular surface of $T$ cells after stimulation by mitogens ${ }^{8}$ and on tumour cells in adult $T$ cell leukaemia.9 ${ }^{9}$ Recent studies have also reported that the soluble form of IL-2R has been detected in the supernatant of $T$ cell cultures by mitogens or antigens ${ }^{10} 11$ and in serum of patients with adult $T$ cell leukaemia, ${ }^{12}$ acquired immune

Accepted for publication 3 February 1989.

Correspondence to Dr Yoshiaki Tokano, Division of Rheumatology, Department of Internal Medicine, Juntendo University School of Medicine, 2-1-1 Hongo, Bunkyo-ku, Tokyo, Japan. deficiency syndrome, ${ }^{12}$ Sézary syndrome, ${ }^{13}$ and Hodgkin's disease. ${ }^{13}$ Thus soluble IL-2R may serve as an index of activated $T$ cells or $T$ cell malignancy.

In this study we determined the concentration of soluble IL-2R in the serum of patients with SLE, who were said to have activated $T$ cells, and correlated the results obtained with the clinical findings. We found that the patients with SLE had significantly higher concentrations of soluble IL-2R than normal controls and that the concentration correlated with disease activity. Therefore, soluble IL-2R may serve as a new clinical indicator in patients with SLE.

\section{Patients and methods}

\section{PATIENTS}

Serum samples were obtained from 54 patients with SLE (50 women, four men; aged 21-49 years), according to the American Rheumatism Association criteria (1982), and from 20 normal subjects matched in age and sex with the patients.

The patients with SLE varied in the degree of severity of their serological indices and clinical symptoms. All patients, apart from two, had been 
receiving steroid treatment $(10-30 \mathrm{mg}$ of prednisolone a day) for from one to 26 years.

\section{DETERMINATION OF SOLUBLE}

INTERLEUKIN 2 RECEPTOR

The concentration of soluble IL-2R was determined by enzyme linked immunosorbent assay (ELISA) as previously reported. ${ }^{10}$ To each well of a 96 well multiplate was added $100 \mu \mathrm{l}$ of a 1:20 dilution of anti-Tac antibody ( $T$ Cell Sciences Inc, Cambridge)

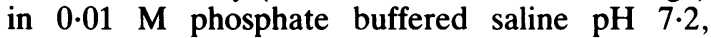
followed by incubation at room temperature for 48 hours. Blocking was carried out with $1 \%$ bovine serum albumin in phosphate buffered saline at $37^{\circ} \mathrm{C}$ for two hours, and then $100 \mu \mathrm{l} /$ well of serum, dilution 1:4, was added and the wells incubated at $37^{\circ} \mathrm{C}$ for an additional two hours. After washing, 100 $\mu \mathrm{l} /$ well of peroxidase conjugated with anti-IL-2R (7G7/B6; T cell Science Inc, Cambridge) was added and incubated at $37^{\circ} \mathrm{C}$ for a further two hours. After washing, $100 \mu \mathrm{l} /$ well of $o$-phenylenediamine (in citrate buffer $\mathrm{pH} 5.0$ and $\mathrm{H}_{2} \mathrm{O}_{2}$ ) was added and left for 30 minutes at room temperature. Finally, 100 $\mu \mathrm{l} /$ well of $2.5 \mathrm{M} \mathrm{H}_{2} \mathrm{SO}_{4}$ was added to terminate the reaction and the optical density at $490 \mathrm{~nm}$ was determined. The same procedure was applied to the reference reagent, which was prepared from the culture supernatant of normal interleukin 2 dependent human $\mathrm{T}$ cell line four days after stimulation with $10 \%$ interleukin 2 . The undiluted reagent was assigned a concentration of 3200 units $/ \mathrm{ml}$, and serial dilutions of $1: 1,1: 2,1: 4$, and 1:16 were used to formulate a reference curve. The concentration of soluble IL-2R in the serum samples from the patients with SLE was determined by comparison with this reference curve.

DETERMINATION OF ANTI-DNA ANTIBODIES AN D $\mathrm{CH}_{50}$

Determination of anti-DNA antibodies was by the Farr assay ${ }^{14}$ and of $\mathrm{CH}_{50}$ by $50 \%$ haemolysis. ${ }^{15}$

DISEASE ACTIVITY OF SLE

The disease activity of each patient was assessed by the activity score described by Lahita et al, ${ }^{16}$ which was graded as follows: $0=$ none; $1=$ false positive serology, raised erythrocyte sedimentation rate, leucopenia, arthritis, rash, low grade fever, mild cutaneous vasculitis; 2 =haemolytic anaemia, thrombocytopenia without bleeding, pleuropericarditis, nephritis without azotaemia, neurological symptoms, severe anaemia, or significantly raised blood pressure; $3=$ more severe nephritis (creatinine $\leqslant 177$ $\mu \mathrm{mol} / \mathrm{l})$, neurological symptoms, mild central nervous system symptoms, and peripheral vasculitis with gangrene; $4=$ life threatening (creatinine $>265$ $\mu \mathrm{mol} / \mathrm{l})$, coma or obtundation, pulmonary haemorrhage, and central nervous system vasculitis.

STATISTICAL ANALYSIS

The statistical significance of the difference in concentration of soluble IL-2R between the patients?

Soluble IL-2R
$(\mathrm{U} / \mathrm{m} \ell)$

$\uparrow$ Patients with Normal subjects

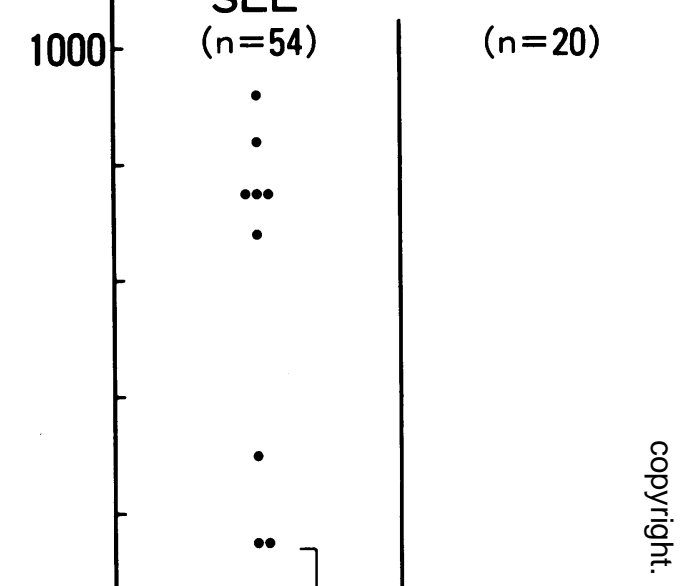

\section{(n)}


with SLE and the normal subjects was obtained with the Wilcoxon rank sum test. Correlation between the concentration of soluble IL-2R and the titre of anti-DNA antibodies, $\mathrm{CH}_{50}$, or disease activity was evaluated with Student's $t$ test. Difference in the incidence of the clinical manifestations was evaluated with the $\chi^{2}$ test.

\section{Results}

\section{CONCENTRATIONS IN SOLUBLE}

\section{INTERLEUKIN 2 RECEPTOR}

Figure 1 shows the concentrations of soluble IL-2R, assessed by an ELISA, in the serum of 54 patients with SLE and 20 normal subjects. It can be seen that the patients with SLE had significantly higher concentrations of soluble IL-2R, ranging from 80 to $960 \mathrm{U} / \mathrm{ml}(345 \cdot 2$ (SD 222.59)) than the normal subjects, whose range was between 90 and $310 \mathrm{U} / \mathrm{ml}$ $(155.05(48.77)) \quad(\mathrm{p}<0.05)$. About $30 \%$ of the patients with SLE had concentrations of soluble IL-2R more than three SD above the mean concentration of the normal subjects. The two patients who were not receiving steroid treatment also had higher concentrations of soluble IL-2R (650 and $840 \mathrm{U} / \mathrm{ml})$.

\section{CLINICAL MANIFESTATION AND}

SEROLOGICAL CHARACTERISTICS

Correlation between the concentration of soluble IL-2R and the increase of clinical manifestations

Table 1 Incidence of clinical manifestations in patients with systemic lupus erythematosus with high concentrations of soluble interleukin 2 receptors and normal concentrations. Number (\%) of patients is shown

\begin{tabular}{lcc}
\hline & \multicolumn{2}{l}{ Soluble interleukin 2 receptor } \\
\cline { 2 - 3 } & $\begin{array}{l}\text { High } \\
\text { concentration } \\
(n=18)\end{array}$ & $\begin{array}{l}\text { Normal } \\
\text { concentration } \\
(n=32)\end{array}$ \\
\hline Malar rash & $15(83)$ & $17(53)$ \\
Discoid & $3(17)$ & $6(19)$ \\
Photosensitivity & $5(28)$ & $9(28)$ \\
Oral ulcer & $10(56)$ & $13(41)$ \\
Joint involvement & $17(94)$ & $26(81)$ \\
Serositis & & \\
Pleuritis & $3(17)$ & $3(9)$ \\
$\quad$ Pericarditis & $7(39)$ & $2(6)$ \\
Central nervous system involvement & \\
Seizure & $3(17)$ & $1(3)$ \\
Psychosis & $2(11)$ & $2(6)$ \\
Haemolytic anaemia & $5(28)$ & $8(25)$ \\
Leucopenia & $4(22)$ & $7(22)$ \\
Lymphopenia & $14(78)$ & $26(81)$ \\
Thrombocytopenia & $4(22)$ & $4(13)$ \\
Renal involvement & $10(56)$ & $10(31)$ \\
\hline
\end{tabular}

${ }^{*} \mathrm{p}<0.05$, comparison with patients with normal concentration of interleukin 2 receptor ( $\chi^{2}$ test).

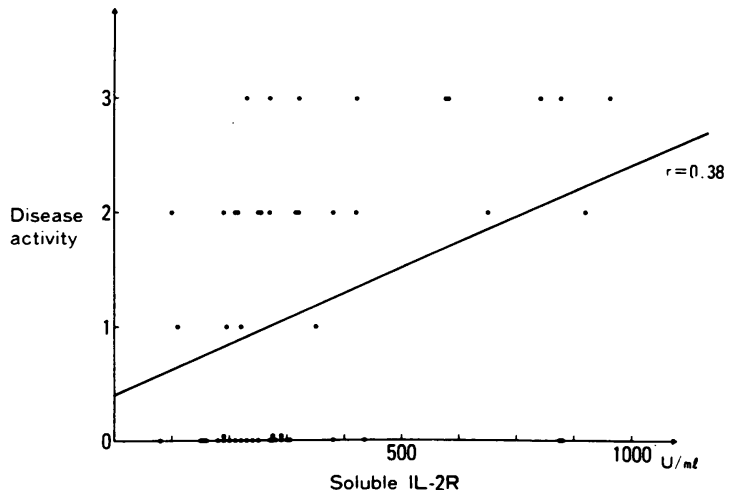

Fig. 2 Correlation between the concentration of soluble interleukin 2 receptor $(I L-2 R)$ and the disease activity score. The disease activity score was obtained as described by Lahita et al. ${ }^{16}$

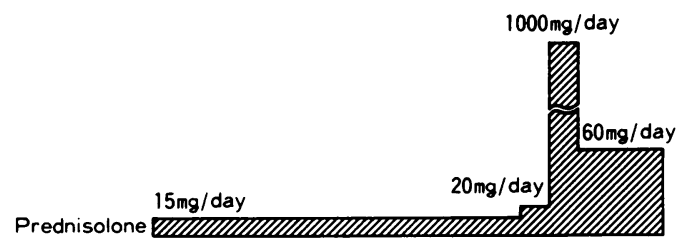

Soluble IL-2R $(U / m \ell)$
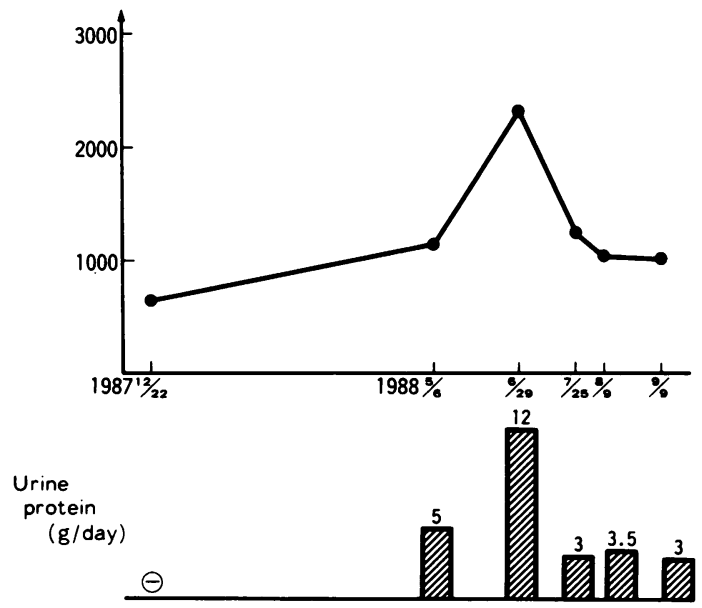

$\mathrm{CH}_{50}(\mathrm{U} / \mathrm{m} \ell) 21.4$

$\begin{array}{lllll}13.0 & 15.4 & 9.0 & 12.2 & 17.9\end{array}$

Anti-DNA 32.1 antibody

$$
\text { (U/me) }
$$

$\begin{array}{llllll}125.2 & 520 & 810 & 47.3 & 34.1\end{array}$

Fig. 3 Longitudinal evaluation of the concentrations of soluble interleukin 2 receptor $(I L-2 R)$ relative to those of anti-DNA antibodies, $\mathrm{CH}_{50}$, and proteinuria, and relative to treatment with prednisolone of patient No 1 with systemic lupus erythematosus and lupus nephritis. The concentration of soluble IL-2R increased with an increase in the amount of urine protein and the concentration of anti-DNA antibodies, and with a decrease in the level of $\mathrm{CH}_{50}$. With treatment these changes improved. 
(according to the criteria of the American Rheumatism Association) throughout the clinical course was investigated. The patients were classified into two groups: patients with high concentrations of soluble IL-2R (group 1) and those with normal concentrations (group 2). The patients in group 1 had concentrations more than three SD above the mean concentration of the normal subjects, whereas those in group 2 had concentrations less than three SD above the concentration of the normal subjects. As shown in Table 1 the incidence of pericarditis was the only clinical manifestation that was greater in patients with high concentrations of soluble IL-2R than in those whose concentrations were normal $(p<0 \cdot 05)$. Pleuritis, central nervous system involvement, and renal involvement also showed a greater incidence in patients with high concentrations of soluble IL-2R, but the differences did not reach statistical significance. No particular correlation was noted with the skin and mucosa (malar rash, discoid, photosensitivity, and oral ulcer), joint and haematological involvement (haemolytic anaemia, lymphocytopenia, and thrombocytopenia).

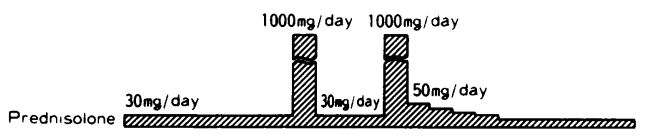

Soluble IL-2R (U/ml)
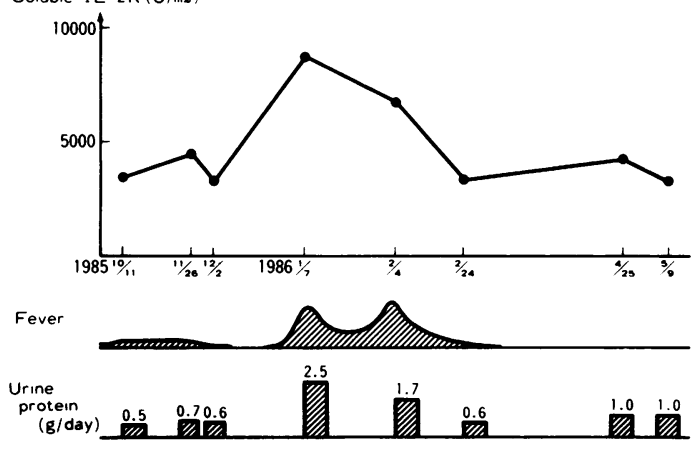

$$
\begin{array}{crrrrrr}
\mathrm{CH}_{50}(\mathrm{U} / \mathrm{ml}) & 6.513 .9 & 13.6 & 20.5 & 24.7 & 33.2 & 37.7 \\
\begin{array}{c}
\text { Ant,-DNA } \\
\text { antibody } \\
(\mathrm{U} / \mathrm{ml})
\end{array} & 13.612 .4 & 14.5 & 4.3 & 10.3 & 14.2 & 15.9 \\
\hline & & & & & &
\end{array}
$$

Fig. 4 Longitudinal evaluation of the concentrations of soluble interleukin 2 receptor $(I L-2 R)$ relative to those of anti-DNA antibodies, $\mathrm{CH}_{50}$, proteinuria, and fever, and relative io treatment with prednisolone of patient No 2 with systemic lupus erythematosus and lupus nephritis. The concentration of soluble IL-2R increased with fever, with an increase in the amount of urine protein, and with a decrease in $\mathrm{CH}_{50}$. With treatment these changes improved. There was no change in the concentration of anti-DNA antibodies during the clinical course.

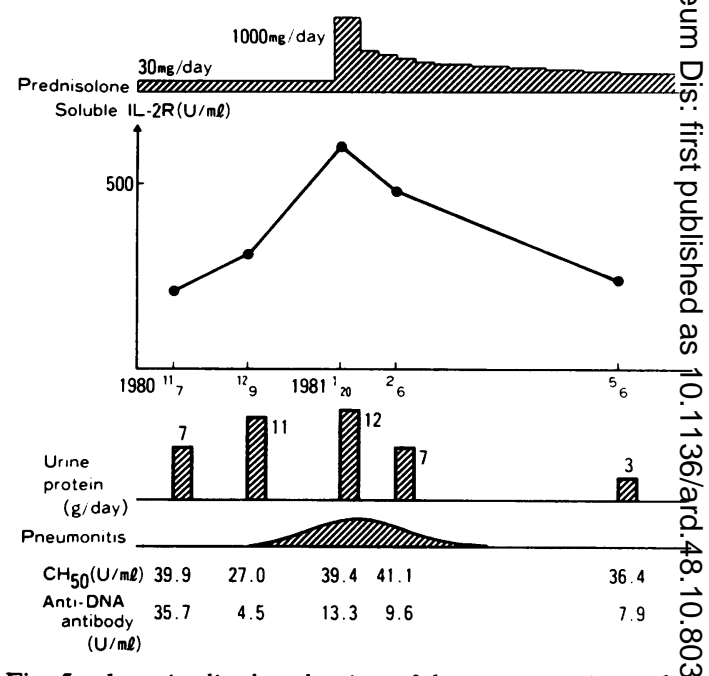

Fig. 5 Longitudinal evaluation of the concentrations of $\mathrm{\omega}$ soluble interleukin 2 receptor $(I L-2 R)$ relative to those of anti-DNA antibodies, $\mathrm{CH}_{50}$, proteinuria, and pneumonitis. and relative to treatment with prednisolone of patient No 3 with systemic lupus erythematosus, lupus nephritis, and $\overrightarrow{0}$ pneumonitis. The concentration of soluble IL-2R increase. with fever, with an increase in the amount of urine protein? and with a worsening of the pneumonitis. With treatme these changes improved. There were no changes in the concentrations of anti-DNA antibodies and $\mathrm{CH}_{50}$.

Correlation between the concentration of solubote IL-2R and the serological characteristics was inves gated by using anti-DNA antibody and the $\mathrm{CH}_{5 \mathrm{~B}}$, which were considered to be the main laborato variables of SLE. There was no significant correla tion between the concentration of soluble IL-2R are anti-DNA antibodies (data not shown), possibdy because some patients with high concentrations of soluble IL-2R have low concentrations of anti-DNG antibodies. Similarly, there was no significant co: relation between the concentration of soluble IL-2\% and $\mathrm{CH}_{50}$ (data not shown).

DISEASE ACTIVITY

As the patients with high concentrations of solub IL-2R tended to have an increased incidence of serositis, central nervous system involvement, and renal involvement the possible correlation between concentration of soluble IL-2R and the disease activity at the time when the serum was prepareg was further investigated by applying the activity score described by Lahita et al. ${ }^{16}$ Figure 2 shows the there was significant correlation between the cow centration of soluble IL-2R and the disease activity $(p<0 \cdot 05)$. Of the 18 patients with high concentrations of soluble IL-2R, 11 belonged to the more severi 
disease activity group (score $>2$ ). The degree of severity in these patients was directly related to the degree of renal involvement (eight cases), serositis (two cases), central nervous system involvement (one case), and peripheral vasculitis (one case).

We also monitored the change in the concentration of soluble IL-2R in four patients during their clinical course. Figures 3-6 show that the concentrations of soluble IL-2R in all cases increased as the amount of urine protein increased, but with treatment these increases and proteinuria were reversed. In some patients pneumonitis, pleuritis, central nervous system involvement, and peripheral vasculitis (skin ulcer) also related to the concentration of

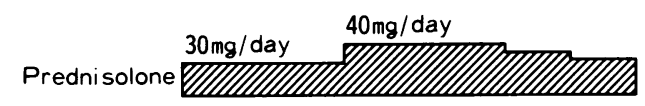

Soluble IL-2R $(U / m \ell)$
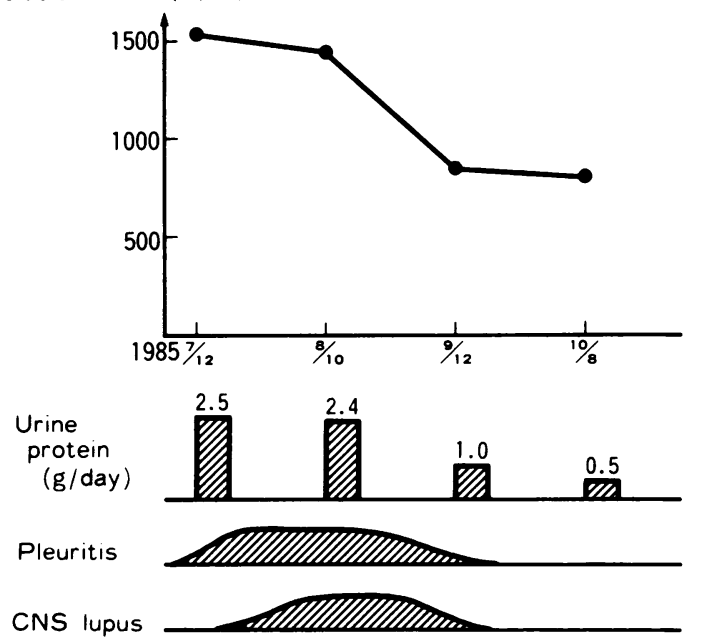

Skin-ulcer

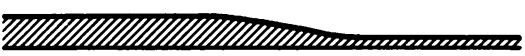

$\begin{array}{ccccr}\mathrm{CH}_{50}(\mathrm{U} / \mathrm{m} \ell) & 28.4 & 24.4 & 22.2 & 27.6 \\ \begin{array}{c}\text { Anti-DNA } \\ \text { antibody } \\ (\mathrm{U} / \mathrm{m} \ell)\end{array} & 33.8 & 42.2 & 15.0 & 3.4 \\ & & & & \end{array}$

Fig. 6 Longitudinal evaluation of the concentrations of soluble interleukin 2 receptor $(I L-2 R)$ relative to those of anti-DNA antibodies, $\mathrm{CH}_{50}$, proteinuria, central nervous system (CNS) involvement, and peripheral vasculitis, and relative to treatment with prednisolone of patient No 4 with systemic lupus erythematosus, lupus nephritis, CNS lupus, and peripheral vasculitis. The concentration of soluble $I L-2 R$ increased with an increase in the amount of urine protein and the concentration of anti-DNA antibodies, and with worsening of the CNS involvement and peripheral vasculitis. With treatment these changes improved. There was no change in the level of $\mathrm{CH}_{50}$. soluble IL-2R. Levels of anti-DNA antibodies and $\mathrm{CH}_{50}$ also varied with the disease activity in most patients, but there were no changes in the levels of anti-DNA antibodies or $\mathrm{CH}_{50}$ during the clinical course in some patients (Figs 4, 5, and 6).

\section{Discussion}

Although cellular surface IL-2R, the receptor for transferrin, or class II antigen (HLA-DR) on T cells are believed to be markers of activated T cells, ${ }^{8} 1718$ recent studies have reported that IL-2R also appears in the culture supernatant or in the serum, or both, during $\mathrm{T}$ cell proliferation, ${ }^{10}{ }^{11}$ which suggests that soluble IL-2R may also be a marker of activated $T$ cells. The concentration of soluble IL-2R was determined by an ELISA using two standard monoclonal antibodies. ${ }^{10}$ Soluble IL-2R was easily distinguished from the other markers of activated $T$ cells (cellular surface IL-2R, the receptor for transferrin, or class II antigen) by this method as serum is used in an ELISA and other markers are determined by flow cytometry.

Previous reports have stated that patients with SLE have activated T cells, ${ }^{67}$ and therefore we determined the concentration of soluble IL-2R in patients with SLE as another indicator of $T$ cell activation. It was found that the concentrations of soluble IL-2R in patients with SLE were significantly higher than in normal subjects. This result agrees with other studies ${ }^{19}{ }^{20}$ and further supports the existence of activated $T$ cells in patients with SLE. Even though the patients in our study had been receiving steroid treatment, we believe that the result does not reflect this use of steroids because patients who were not receiving steroids also had increased concentrations of soluble IL-2R; the concentration of soluble IL-2R in the lupus mouse was also increased. ${ }^{21}$

We further investigated the correlation between concentration of soluble IL-2R and the clinical findings. Although we were unable to find any statistically significant correlation between the concentration of soluble IL-2R and specific clinical manifestations, the incidence of pericarditis was significantly greater $(p<0.05)$ in patients with high concentrations of soluble IL-2R than in patients within the normal range. Even though there was no statistically significant correlation with pleuritis, central nervous system involvement, and renal involvement, it is important to point out that these conditions tended to prevail among patients with a high concentration of soluble IL-2R. Further, as the serum was obtained randomly from the patients with SLE instead of during the active and inactive phases of the disease and we were unable to monitor the 
concentration of soluble IL-2R throughout the disease course of all patients, these results suggest that even patients within the normal range might have had increased concentrations during the active phase of pleuritis, central nervous system involvement, and renal involvement. Therefore, we investigated the correlation between the concentration of soluble IL-2R and disease activity at the time when the serum was obtained and prepared. From these results we found that the concentration of soluble IL-2R correlated with disease activity, especially with renal involvement, serositis, central nervous system involvement, and peripheral vasculitis. In addition, we also noticed that the concentration of soluble IL-2R increased with an increase in the activity of the disease and decreased with treatment in some patients, thus supporting a correlation between concentrations of soluble IL-2R and disease activity. Although another study reported similar results in a patient with lupus nephritis, ${ }^{19}$ it is interesting that the correlation between concentration of soluble IL-2R and disease activity was also found in patients with serositis, central nervous system involvement, and peripheral vasculitis. There was no significant correlation between the concentration of soluble IL-2R and anti-DNA antibodies and $\mathrm{CH}_{50}$. Although anti-DNA antibodies and $\mathrm{CH}_{50}$ are usually used as indices of disease activity in patients with SLE, especially lupus nephritis, it is known that a correlation is not shown in all cases. Furthermore, the titre of anti-DNA antibodies and $\mathrm{CH}_{50}$ did not change in some patients monitored during the clinical course. Thus these results suggest that soluble IL-2R may be a new marker of disease activity independent of anti-DNA antibodies or $\mathrm{CH}_{50}$.

The mechanism regulating the secretion or biological role of soluble IL-2R is not clearly understood and this poses some problems. Firstly, cellular surface IL-2R of the peripheral blood lymphocytes does not increase in our patients with high concentrations of soluble IL-2R (data not shown), whereas both types of IL-2R increased in patients with adult T cell leukaemia. ${ }^{912}$ The reason for this is not clear, but we believe that it may be due to the shedding of cellular surface IL-2R as previously reported ${ }^{22}$ or an increase of cellular surface IL-2R in the lymphoid organ. The second problem is whether soluble IL-2R has an immunoregulatory role or not. A previous report suggested that soluble IL-2R competed with cellular surface IL-2R for the interleukin 2 and therefore reduction of activated $T$ cells occurred. ${ }^{10}$ Soluble IL-2R in patients with SLE may also serve the same purpose as a recent report indicates that the concentration of interleukin 2 in the serum of patients with SLE increases with $T$ cell activation. ${ }^{20}$ We think that this theory should be carefully evaluated, however, because it has bee? reported that soluble IL-2R binds with low affinity. ${ }^{23}$ The third problem is whether the soluble IL-2R of patients with SLE is derived from the cells only or not. Other studies have reported the soluble IL-2R is derived not only from $T$ cells bu also from B cells, ${ }^{2124}$ and it is known that B ce abnormality exists in patients with SLE. Therefore we cannot disregard the possibility that soluble IL-2R is also derived from $B$ cells. As the concentrap tion of soluble IL-2R derived from $B$ cells is minut $\vec{e}$ in comparison with that from $\mathrm{T}$ cells, ${ }^{24}$ however, w believe that the soluble IL-2R in the serum of patients with SLE is derived mostly from the T cells? Although the role of soluble IL-2R is not yet clear, $\stackrel{\phi}{\mathrm{p}}$ may be an important clue in the investigation of th $\vec{s}$ pathogenesis of SLE.

\section{References}

1 Smolen J S, Chused T M, Leiserson W M, Reeves J P, Allirg D, Steinberg A D. Heterogeneity of immunoregulatory T-cell subsets in systemic lupus erythematosus. Am J Med 1982; 72 783-90.

2 Smith J B, Talal N. Significance of self-recognition and interleukin-2 for immunoregulation, autoimmunity and cafesco Scand J Immunol 1982; 16: 269-78.

3 Sakane T, Steinberg A D, Green I. Failure of autologous med lymphocyte reactions between $T$ and non- $T$ cells in patient systemic lupus erythematosus. Proc Natl Acad Sci USA 75: $3464-8$.

4 Alcocer-Varela J, Alarcón-Segovia D. Decreased production of and response to interleukin- 2 by cultured lymphocytes fro patients with systemic lupus erythematosus. J Clin Invest 1980, 69: $1388-92$.

5 Linker-Israeli M, Bakke A C, Kitridou R C, Gendler S, Gil S, Horwitz D A. Defective production of interleukin 1 and interleukin 2 in patients with systemic lupus erythematos (SLE). J Immunol 1983; 130: 2651-5.

6 Yu D T Y, Winchester R J, Fu S M, Gibofsky A, Ko H Kunkel H G. Peripheral blood Ia-positive T cells. Increases certain diseases and after immunisation. J Exp Med 1980; 151 91-100.

7 Hirano T, Hashimoto H, Okumura K, et al. The appearance $\mathrm{Ia}^{+} \mathrm{T}$ cell in systemic lupus erythematosus. In: Kano K, Mori \& Sugisaki T, Torisu M, eds. Cellular, molecular and genes approaches to immunodiagnosis and immunotherapy. Tokyg: University of Tokyo Press, 1987: 441-5.

8 Smith K A. T-cell growth factor. Immunol Rev 1980; 5D. 337-57.

9 Tsudo M, Uchiyama T, Uchino H, Yodoi J. Failure $\overline{\bar{R}}$ regulation of Tac antigen/TCGF receptor on adult T-ceth leukemia cells by anti-Tac monoclonal antibody. Blood 1983; 61: 1014-6.

10 Rubin L A, Boutin B, Nelson D L, et al. Soluble interleukin receptors are released from activated human lymphoid cells if vitro. J Immunol 1985; 135: 3172-7.

11 Reske-Kunz A B, Osawa H, Josimovic-Alasevic O, Rüde $\mathscr{C}$ Diamantstein T. Soluble interleukin 2 receptors are released long term cultured insulin-specific $T$ cells transiently aft contact with antigen. J Immunol 1987; 138: 192-6.

12 Mackeen L, Hinuma Y, Purtilo D, et al. Serum interleukinreceptor as a marker for active $\mathrm{T}$ cell malignancies. Fed Pro 1986; $45: 454$. 
13 Nelson D L. Soluble interleukin-2 receptors: analysis in normal individuals and in certain disease states. Fed Proc 1986; 45: 377.

14 Pincus T, Schur P H, Rose J A, Decker J L, Talal N. Measurement of serum DNA binding activity in SLE. $N$ Engl $J$ Med 1969; 281: 701-5.

15 Mayer M M. Complement and complement fixation. In: Experimental immunochemistry. 2nd ed. Springfield, Illinois: Thomas, 1961: 133-240.

16 Lahita R G, Bradlow H L, Ginzler E, Pang S, New M. Low plasma androgens in women with systemic lupus erythematosus. Arthritis Rheum 1987; 30: 241-8.

17 Trowbridge I S, Omary M B. Human cell surface glycoprotein related to cell proliferation is the receptor for transferrin. Proc Natl Acad Sci USA 1981; 78: 3039-43.

18 Ko H S, Fu S M, Winchester R J, Yu D T Y, Kunkel H G. Ia determinants on stimulated human $\mathrm{T}$ lymphocytes. Occurrence on mitogen- and antigen-activated T cells. J Exp Med 1979; 150: 246-55.

19 Wolf R E, Brelsford W G. Soluble interleukin-2 receptors in systemic lupus erythematosus. Arthritis Rheum 1988; 31: 729-35.
20 Huang Y, Perrin L H, Miescher P A, Zubler R H. Correlation of $T$ and $B$ cell activities in vitro and serum IL-2 levels in systemic lupus erythematosus. $J$ Immunol 1988; 141: 827-33.

21 Balderas R S, Josimovic-Alasevic O, Diamantstein T, Dixon F J, Theofilopoulos A N. Elevated titres of cell-free interleukin 2 receptor in serum of lupus mice. J Immunol 1987; 139: 1496-500.

22 Osawa H, Josimovic-Alasevic O, Diamantstein T. Interleukin 2 receptors are released by cells in vitro and in vivo. $\mathrm{I}$. Detection of soluble IL 2 receptors in cell culture supernatants and in the serum of mice by an immunoradiometric assay. Eur J Immunol 1986; 16: 467-9.

23 Jacques Y, Mauff B L, Boeffard F, Godard A, Soulillou J. A soluble interleukin 2 receptor produced by a normal alloreactive human $T$ cell clone binds interleukin 2 with low affinity. $J$ Immunol 1987; 139: 2308-16.

24 Nelson D L, Rubin L A, Kurman C C, Fritz M E, Boutin B. An analysis of the cellular requirements for the production of soluble interleukin-2 receptors in vitro. J Clin Immunol 1986; 6: 114-20. 